\title{
The use of the superior gluteal artery perforator flap to cover sacral defects
}

\author{
Fazlur Rahman M*, Aleezay Haider and Muhammad Asif Ahsan \\ Department of Plastic and Reconstructive Surgery, Aga Khan University, Karachi, Pakistan
}

\begin{abstract}
Objective: To describe our experience of using superior gluteal artery perforator flap for coverage of sacral defects.

Results: We report the use of the superior gluteal artery perforator flap, a skin-subcutaneous tissue flap to repair and reconstruct sacral defects in six patients. The procedures were done for defects of the sacral area. Flap size ranged from $20 \times 9 \mathrm{~cm}$ to $9 \times 4 \mathrm{~cm}$. All flaps survived completely and all donor sites were closed primarily without any donor site complication.
\end{abstract}

Conclusion: We believe that the superior gluteal artery perforator flap is a suitable option for defects in the sacral area. However, more studies with larger numbers are required before it can become a mainstay for this region.

\section{Introduction}

The gluteal region is a commonly used donor site for flaps. Fujino et al. were the first to describe using the gluteal region as a donor site [1]. Improving upon the gluteal myocutaneous flap led Allen and Tucker [2] to introduce the superior gluteal artery flap (SGAP) in 1993 that not only had a longer vascular pedicle but also kept the underlying gluteus maximus muscle intact by dissecting the perforating vessels from the surrounding tissue down to the SGA [3]. Koshima et al. [4] popularized the SGAP flap and since then the technique has had a variety of uses ranging from repair of sacral pressure sores [5] to breast reconstruction [6].

Raising the SGAP flap harvests a robust amount of highly vascular tissue that leaves behind a scar at the donor-site that can be easily concealed [7]. A long vascular pedicle of length $8.5-10 \mathrm{~cm}$ makes the flap very mobile and enables the surgeon to cover large defects. Moreover, the SGAP flap has shown to be beneficial in non-paralyzed patients since it keeps functional muscle intact [5].

For the reasons outlined above, the SGAP flap has become an important method to repair large sacral bedsores along with other sacrococcygeal defects. We report here our early experience with using SGAP in six patients.

\section{Operative Technique}

The procedure is performed under general anesthesia with the patient in prone position. Complete excision of non-viable tissue and proper wound debridement is necessary. Perforators above the piriformis muscle are used since the SGA supplies the suprapiriformis region of the gluteus maximus. The location of the perforators is superior to a line drawn between the greater trochanter of the femur and a point halfway between the posterior superior iliac spine (PSIS) and the coccyx (Figure 1). The perforators are found adjacent to the medial two-thirds of this line [8].

The flap is raised by incising the superior border and looking for the perforator in the suprafascial plane. Once a perforator is identified the fascia is incised and perforator followed to the underlying vessel. The vessel direction is visualized and other perforators located along the vessel path. At least two perforators are taken and lateral perforators are preferred as they provide a wider arc of movement [5]. The number of perforators selected varies and depends on patient anatomy [7]. Loupe magnification is used to dissect the vessel from between the muscle fibers and to ligate muscular side branches [2]. The patient suffers less pain and is quick to mobilize since the muscle is split and not cut [6]. Dissection is meticulous and time-consuming as flap is bulky and muscular innervation and blood supply needs to be preserved. Once flap is elevated it is left in place for ten minutes and bleeding checked at edges. Then the flap is transposed into the defect. The donor-site is closed primarily after the flap is transposed into the defect. Drains are placed under the flap and donor-site. The patient is kept in a lateral position post-operatively and the flap is carefully monitored.

\section{Materials and Methods}

ERC approval was taken for the study. There were six patients included in the study. All patients had wounds in the sacral region requiring flap coverage. Time duration was from March 2016 to December 2017.

\section{Results}

There were six patients within our study (Table 1). All patients were males with ages ranging from 19 to 62 years (mean 41 years). Two patients had neoadjuvant radiation followed by abdominoperineal resection with wounds at the sacral region, two patients had sacral pressure sores, one had a recurrent pilonidal sinus and one had a

${ }^{\star}$ Correspondence to: $\mathrm{M}$ Fazlur Rahman, Department of Plastic and Reconstructive Surgery, Aga Khan University, Karachi, Pakistan, E-mail: fazli8@ yahoo.com

Received: March 25, 2018; Accepted: April 10, 2018; Published: April 20, 2018 
Table 1. Patients included within the study with demographic information and SGAP flap size and number of perforators. Number 2 and 3 (highlighted in bold) have been described in detail.

\begin{tabular}{|c|c|c|c|c|c|}
\hline Number & Sex & Age/years & Defect Cause & Flap Size/cm & Number of Perforators \\
\hline 1 & Male & 57 & Recurrent sacral chondroma & $17 \times 9$ & 2 \\
\hline 2 & Male & 27 & Sacral pressure sore & $14 \times 6$ & 1 \\
\hline 3 & Male & 42 & Post-APR wound & $20 \times 9$ & 3 \\
\hline 4 & Male & 19 & Recurrent pilonidal sinus & $9 \times 4$ & 2 \\
\hline 5 & Male & 42 & Sacral pressure sore & $15 \times 8$ & 2 \\
\hline 6 & Male & 62 & Post-APR wound & $20 \times 6 \mathrm{cms}$ & 2 \\
\hline
\end{tabular}

\section{Case 2}

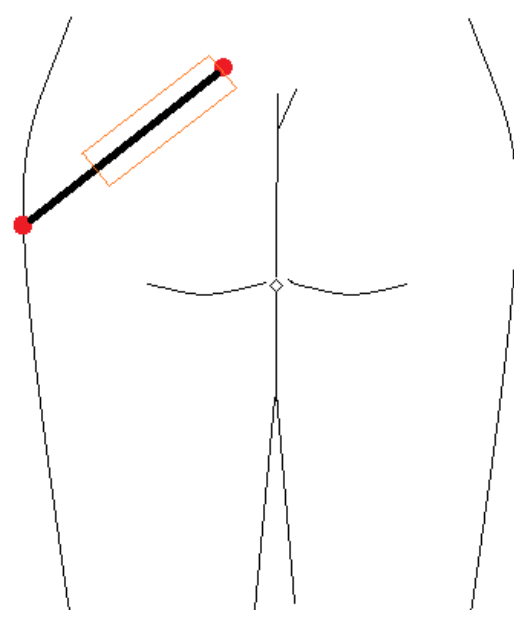

Figure 1. Landmarks to identify superior gluteal artery perforators. Red circles mark the greater trochanter and posterior superior iliac spine. Orange rectangle marks the medial two-thirds of the line, adjacent to which are the perforators.

recurrent sacral chondroma. In all these cases plastic surgery was taken on board for flap coverage only. The largest flap size taken was $20 \times 9$ $\mathrm{cm}$ and the smallest was $9 \times 4 \mathrm{~cm}$. The largest flap harvested was for the post-APR defect and was based on three perforators. The SGAP flap harvested for the 27-years-old gentleman with the sacral pressure-sore was based on one perforator while the remaining 4 flaps were raised with two perforators. All donor sides were closed primarily and all flaps survived completely and wounds healed in 2 weeks with no donor side morbidity. All patients were followed for 6 weeks postoperatively till to make sure that wounds were completely healed. Two of the five cases (Number 2-3, Table 1) have been elaborated.

\section{Case 1}

A 27-years-old male (Number 2, Table 1) had a gunshot injury which resulted in an above the knee amputation of his left lower limb and a colostomy. He developed two sacral pressure sores during the hospital stay. A smaller pressure sore on the left side and a larger pressure sore on the right side. There was a bridge of skin between the two pressure sores. Early wound coverage of the pressure sores was required for prosthesis placement and reversal of colostomy.

Following debridement, a flap measuring $14 \times 6 \mathrm{~cm}$ based on one SGA perforator was harvested and transposed onto the sacral bedsore on the right side. The smaller defect on the left side was repaired using a rotational fasciocutaneous flap harvested from the left side. Donor defects were closed primarily (Figure 2). Post-operatively, the patient was kept in a lateral position and was given a high-protein diet. The flaps were monitored and the patient underwent stump physiotherapy. The healing process was uneventful and the patient was discharged on the fourth post-operative day. The patient remained fine and the wound healed in 2 weeks.
A 42-years-old male (Number 3, Table 1) had undergone an APR for colorectal carcinoma and had received radiation within the area. The patient had been previously infected with Hepatitis B and had been HBV-DNA negative since 4 months.

After all aseptic measures were taken, the patient was placed in a prone jackknife position. An elliptical incision was made around the irradiated skin. The defect, located within the intergluteal cleft, which measured $5 \times 4 \mathrm{~cm}$ before debridement was dissected till the level of bone. A much larger flap of $20 \times 9 \mathrm{~cm}$ based on three SGA perforators was harvested and moved into the defect since the defect's longest dimension was its depth. The SGAP flap was folded and placed inside the wound after de-epithelization to fill dead space (Figure 3). Drainage was applied. Daily dressings were done post-operatively and flap health was closely monitored. The patient was discharged on the sixth postoperative day. A follow-up in clinic visit two-weeks after the procedure showed an intact flap with good healing.

\section{Discussion}

Defects of the sacral area need soft tissue coverage with thick flaps as these areas are prone to developing pressure sores and recurrence of the sores is common. Fortunately, the gluteal region has extensive vascular supply from the superior and inferior gluteal arteries. There are three different flaps that can be elevated based on the gluteal arteries. These include the gluteus maximus musculocutaneous flap, the gluteus maximusfasciocutaneous flap and the gluteal artery perforator flap.

Traditionally, the gluteus maximus musculocutaneous flap has been used for closure of sacral area defects. First described by Ramirez [9] in 1984 it was widely used as it had a robust blood supply. However, problems associated with it included limited flap movement and excessive blood loss [10]. A defect with width more than $5 \mathrm{~cm}$ required bilateral flaps as the superior gluteal artery emerges approximately 5 $\mathrm{cm}$ from the midline [11]. There was also loss of functional muscle which was an important limitation in ambulatory patients. Pedicled fasciocutaneous flaps first described in 1988 have also been used to cover sacral defects [12]. They have rotational movement with limited mobility. This flap is usually sutured under tension and can get easily dehisced. The advantage of this flap is that it can be reused again by administering another incision and advancing the flap further $[13,14]$.

The gluteal artery perforator flap was first described by Koshima in 1993 [4] and has gained popularity recently $[3,7,15]$. The dissection of the perforator can lead to a pedicle length of $8-10 \mathrm{~cm} \mathrm{[5].} \mathrm{A} \mathrm{long}$ vascular pedicle also means there is greater mobility of the flap and tension free closure. Verpaele et al. [5] described the movement of the flap as a translation while Chen et al. [14] stated that the perforator flap can be rotated, advanced and transposed onto the defect or used as a propeller flap.

Both fasciocutaneous flaps and perforator flaps have muscle preservation, less donor site morbidity, less blood loss and less 


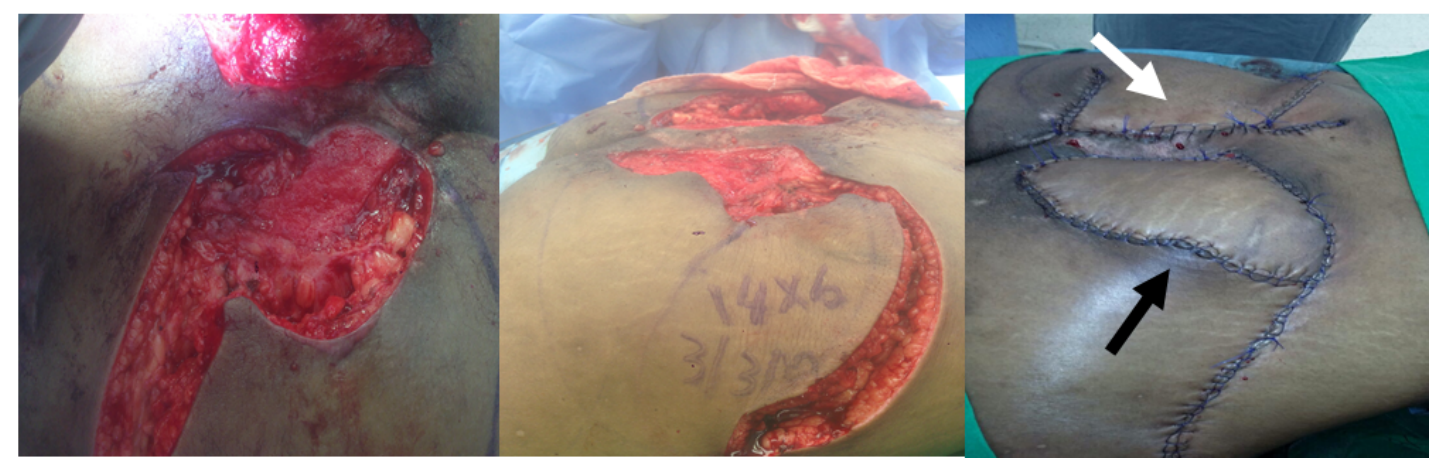

Figure 2. (Left) Bridge of skin separating large sacral defect on right side from smaller defect on left. (Middle) SGAP flap traced measuring $14 \mathrm{x} 6 \mathrm{~cm}$ to be transposed onto defect. (Right) SGAP flap (black arrow) transposed onto defect with rotational flap (white arrow) raised on left, closed primarily with no tension on the suture lines.

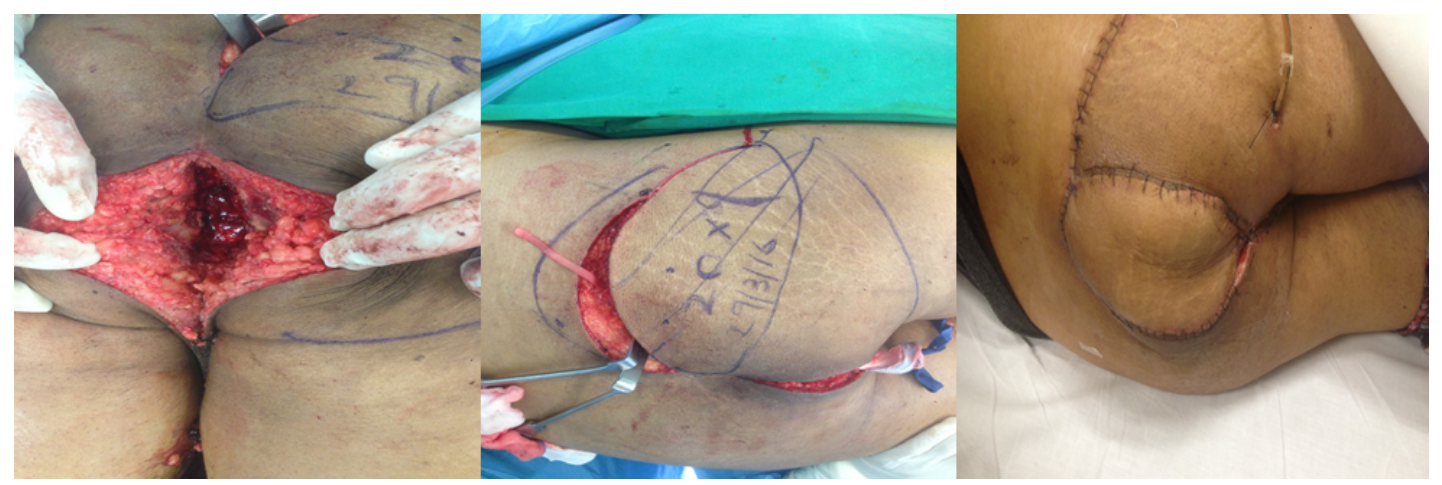

Figure 3. (Left) Abdominoperineal resection defect before debridement measuring $5 \times 4 \mathrm{~cm}$. (Middle) SGAP flap measuring $20 \times 9 \mathrm{~cm}$ traced and raised based on three perforators. (Right) Flap is transposed onto the defect and the donor site closed primarily.

postoperative pain [13]. Problems with perforator flaps include variable anatomy, tedious dissection and risk of venous congestion [15]. Comparing fasciocutaneous flaps to perforator flaps Chen et al. reported a lower rate of dehiscence $(6.45 \%)$ in gluteal perforator flaps compared to fasciocutaneous flaps for which the rate was $18.75 \%$. Although the difference was statistically insignificant it was attributed to the small number of cases within the study [14]. Sameem et al. also did not find any statistical difference between musculocutaneous, fasciocutaneous and perforator flaps [16].

In our study all the flaps were SGAP flaps in which the donor-site is closed primarily to avoid tension between the flap and defect, and prevent dehiscence [17]. Dehiscence has also been attributed to tension in the flap. We shifted to doing SGAP flaps as we had expeirenced dehiscence due to tension with our fasciocutaneous flaps.

Studies suggest that multiple codominant perforators create an enhanced vascular inflow that reduces chances of flap failure [18-20] especially if the flap volume is excessive or if there is an increased risk of flap necrosis [21]. Although it is difficult to determine the vascular territory and hence the utility of each perforator, an anatomical study by Ahmedzadeh et al., found that the average cutaneous SGA vascular territory was $69 \pm 56 \mathrm{~cm}^{2}$ and that $5 \pm 2$ cutaneous perforators greater than or equal to $0.5 \mathrm{~mm}$ were found on average within the gluteal region. It can hence be expected that another perforator would contribute to flap viability [8]. However, multiple perforators in the pedicle restrict the mobility of the flap reducing the range of movement. Therefore, the number of perforators selected is a trade-off between flap mobility and viability and is unique to the patient's specific anatomy. Having more perofrators also allowed us to raise larger flaps. In our second case we had to fill in dead space and having a large flap was especially helpful.
Limitations of this study include a small sample size along with dissimilar designs of each SGAP flap due to anatomical variation in perforator distribution, size of defect and differences in tissue elasticity. However, the location of the defect was always in the sacrum and none of the patients were paralyzed. In conclusion, we believe the SGAP flap to be an accpetable choice for sacral defect repair. However, more studies with adequate sample sizes must be carried out to elucidate SGAP advantages and pitfalls.

\section{References}

1. Fujino T, Harashina T, Aoyagi F, Goldwyn RM (1975) Reconstruction for Aplasia of the Breast and Pectoral Region by Microvascular Transfer of a Free Flap from the Buttock. Plast Reconstr Surg 56: 335.

2. Allen RJ, Tucker C. Superior Gluteal Artery Perforator Free Flap for Breast Reconstruction. Plast Reconstr Surg 95: 1207-12. [Crossref]

3. Lotempio MM, Allen RJ (2010) Breast Reconstruction with SGAP and IGAP Flaps. Plast Reconstr Surg 126: 393-401. [Crossref]

4. Koshima I, Moriguchi T, Soeda S, Kawata S, Ohta S, et al. (1993) The gluteal perforator-based flap for repair of sacral pressure sores. Plast Reconstr Surg 91: 678683. [Crossref]

5. Verpaele A, Blondeel P, Landuyt K, Tonnard P, Decordier B, et al. (1999) The superior gluteal artery perforator flap: an additional tool in the treatment of sacral pressure sores. Br J Plast Surg 52: 385-91. [Crossref]

6. Blondeel P (1999) The sensate free superior gluteal artery perforator (S-GAP) flap: a valuable alternative in autologous breast reconstruction. Br J Plast Surg 52: 185-93. [Crossref]

7. Hunter C, Moody L, Luan A, Nazerali R, Lee GK (2016) Superior Gluteal Artery Perforator Flap: The Beauty of the Buttock. Ann Plast Surg 76: S191-195. [Crossref]

8. Ahmadzadeh R, Bergeron L, Tang M, Morris SF (2007) The Superior and Inferior Gluteal Artery Perforator Flaps. Plast Reconstr Surg 120: 1551-6. [Crossref] 
9. Ramirez OM, Orlando JC, Hurwitz DJ (1984) The sliding gluteus maximus myocutaneous flap: its relevance in ambulatorypatients. Plast Reconstr Surg 74: 68-75. [Crossref]

10. Parry SW, Mathes SJ (1982) Bilateral gluteus maximus myocutaneous advancement flaps: sacral coverage for ambulatory patients. Ann Plast Surg 8: 443-445. [Crossref]

11. Minami RT, Mills R, Pardoe R (1977) Gluteus maximus myocutaneous flaps for repair of pressure sores. Plast Reconstr Surg 60: 242-9. [Crossref]

12. Park C, Park BY (1988) Fasciocutaneous V-Y advancement flap for repair of sacral defects. Ann Plast Surg 21: 23-26. [Crossref]

13. Wong TC, Ip FK (2005) Comparison of gluteal fasciocutaneous rotational flaps and myocutaneous flaps for the treatment of sacral sores. Int Orthop 30: 64-7. [Crossref]

14. Chen YC, Huang EY, Lin PY (2014) Comparison of gluteal perforator flaps and gluteal fasciocutaneous rotation flaps for reconstruction of sacral pressure sores. J Plast Reconstr Aesthet Surg 67: 377-82. [Crossref]

15. Seyhan T, Ertas NM, Bahar T, Borman H (2008) Simplified and Versatile Use of Gluteal Perforator Flaps for Pressure Sores. Ann Plast Surg 60: 673-8. [Crossref]
16. Nojima K, Brown SA, Acikel C, Arbique G, Ozturk S, et al. (2005) Defining Vascular Supply and Territory of Thinned Perforator Flaps: Part I. Anterolateral Thigh Perforator Flap. Plast Reconstr Surg 116: 182-93. [Crossref]

17. Sameem M, Au M, Wood T, Farrokhyar F, Mahoney J (2012) A Systematic Review of Complication and Recurrence Rates of Musculocutaneous, Fasciocutaneous, and Perforator-Based Flaps for Treatment of Pressure Sores. Plast Reconstr Surg 130: 67e-77e. [Crossref]

18. Harashina T, Sone K, Inoue T, Fukuzumi S, Enomoto K (1987) Augmentation of circulation of pedicled transverse rectus abdominis musculocutaneous flaps by microvascular surgery. Br J Plast Surg 40: 367-70. [Crossref]

19. Takayanagi S, Ohtsuka M (1989) Extended Transverse Rectus Abdominis Musculocutaneous flap. Plast Reconstr Surg 83: 1057-60. [Crossref]

20. Semple JL (1994) Retrograde Microvascular Augmentation (Turbocharging) of a Single-Pedicle TRAM Flap through a Deep Inferior Epigastric Arterial and Venous Loop. Plast Reconstr Surg 93: 109-17. [Crossref]

21. Wagner DS, Michelow BJ, Hartrampf CR Jr (1991) Double-Pedicle TRAM Flap for Unilateral Breast Reconstruction. Plast Reconstr Surg 88: 987-97. [Crossref]

Copyright: (C2018 Rahman FM. This is an open-access article distributed under the terms of the Creative Commons Attribution License, which permits unrestricted use, distribution, and reproduction in any medium, provided the original author and source are credited. 